\title{
Editorial
}

\section{Domestic violence during pregnancy: a neglected and unseen public health problem}

\author{
Pallavi R. Shidhaye ${ }^{1}$, Purushottam A. Giri
}

\begin{abstract}
${ }^{1}$ Department of Community Medicine (PSM), L. N. Medical College \& Research Centre, Bhopal, M.P., India
${ }^{2}$ Department of Community Medicine (PSM), Rural Medical College of Pravara Institute of Medical Sciences (Deemed University), Loni, Maharashtra, India
\end{abstract}

\section{*Correspondence:}

Dr. Pallavi R. Shidhaye,

E-mail: drpallavikanade@gmail.com

Copyright: (C) the author(s), publisher and licensee Medip Academy. This is an open-access article distributed under the terms of the Creative Commons Attribution Non-Commercial License, which permits unrestricted non-commercial use, distribution, and reproduction in any medium, provided the original work is properly cited.

According to World Health Organisation (WHO), domestic violence (DV) is defined as psychological/emotional, physical, or sexual violence, or threats of physical or sexual violence that are inflicted on a woman by a family member: an intimate male partner, marital/cohabiting partner, parents, siblings, or a person very well known within the family or a significant other (i.e. former partner) when such violence often takes place in the home. ${ }^{1}$ Intimate partner violence (IPV) and sexual violence against women are major public health problems and violations of human rights. They result in serious short- and long-term physical, sexual and reproductive, and mental health problems, including increased vulnerability to HIV. Near about $15-71 \%$ of women experience physical and/or sexual violence by an intimate partner at some point in their lives. ${ }^{2}$ Violence against women (VAW) affects all phases of lifecycle of a women, as rightly pointed out by WHO, starting from sex selective abortion in prebirth period; female infanticide, female genital mutilation, child marriage or prostitution in childhood; physical, sexual, psychological abuse, rape, sexual harassment, dowry murders, forced pregnancy in adolescence and adulthood period; ending in physical and psychological abuse in elderly. ${ }^{3}$

In recent years, attention has focused also on intimate partner violence during pregnancy due to its prevalence, adverse health consequences and intervention potential. Violence by an intimate partner is manifested by physical, sexual or emotional abusive acts as well as controlling behaviours. The majority of studies on intimate partner violence during pregnancy measure physical violence during pregnancy, although sexual and emotional abuse during pregnancy are also considered as detrimental for women's and their children's well-being. ${ }^{4}$ Domestic violence can result in many negative health consequences for women's health and well-being. Studies on domestic violence illustrate that abused women in various settings had increased health problems such as injury, chronic pain, gastrointestinal, and gynaecological signs including sexually transmitted diseases, depression, and posttraumatic stress disorder. ${ }^{5}$

Intimate partner violence during pregnancy has been found to be associated with fatal and non-fatal adverse health outcomes for the pregnant woman and her baby due to the direct trauma of abuse to a pregnant woman's body, as well as the physiological effects of stress from current or past abuse on fetal growth and development. ${ }^{[4]}$ The most recent Indian National Family Health Survey (NFHS-3, conducted in 2005/2006), a nationallyrepresentative survey of women of reproductive age, estimated that $35 \%$ of ever-married women had experienced physical violence perpetrated by their current or former spouses. In India, overall one-third of women aged 15-49 years had experienced physical violence and one in 10 women had experience of sexual violence as revealed by National Family Health Survey-3. ${ }^{6}$ Over 1.5 million women are victims of physical, sexual, and emotional abuse by former or present intimate partners. Intimate Partner Violence (IPV) around pregnancy can lead to devastating health consequences to mothers and infants. ${ }^{7}$

The prevalence of DV against pregnant women varies widely in the literature, ranging from 1.2 to $66 \% .^{8}$ The prevalence regarding IPV during pregnancy has been demonstrated in the first global report of internationally comparable data on populations from 19 countries, ranged between $2.0 \%$ and $13.5 \% .^{9}$ A study carried out by Kimuna SR et al. ${ }^{10}$ showed that the prevalence of physical violence among Indian women is as high as $31 \%$ and that 
of sexual violence is also as high as $8.3 \%$. A recently published meta-analysis of 92 independent studies concerning prevalence and risk factors associated with DV among pregnant women showed an average prevalence of emotional abuse of $28.4 \%$, and prevalence rates of physical abuse and sexual abuse were $13.8 \%$ and $8.0 \%$, respectively. ${ }^{11}$ The findings from the populationbased study of socio-cultural norms around son preference and married Indian women's risk for IPV victimization indicate that cultural preference for sons does not influence women's risk for IPV victimization. ${ }^{12}$ Intimate partner violence results in an increased risk of adverse outcomes. Homicide may be the most common cause of maternal death. Women who are pregnant and the victims of IPV have high rates of stress, are more likely to smoke or use other drugs, deliver a preterm or low birth weight infant, have an increase in infectious complications, and are less likely to obtain prenatal care. ${ }^{13}$ As WHO report showed that women who have been physically and sexually abused by their partners had $16 \%$ more chance of having low birth weight babies, twice chance of having depression and abortion and 1.5 times to acquire HIV infection as compared to women not abused. ${ }^{14}$ A study by Mahenge $\mathrm{B}$ et al. ${ }^{15}$ found that about three out of ten women experienced physical or sexual intimate partner violence during pregnancy by an intimate partner, which was significantly associated with poor mental health symptoms.

Pregnant women whose partners previously abused them had four times greater odds of being abused during pregnancy than those women who had no history of violence. Other risk factors identified for DV among pregnant women were single marital status, lower education, low socioeconomic status, alcohol abuse (above all by the perpetrator), and unintended or unwanted pregnancy. ${ }^{16}$ Violence on pregnant women significantly increased risk for low birth weight infants, pre-term delivery and neonatal death and also affected breast-feeding postpartum. Women preferred an active role to be played by healthcare providers in response to IPV disclosure. ${ }^{17}$ Both 'history of violence' and depressive symptoms detected in early pregnancy can indicate that the woman also is exposed to 'DV during pregnancy'. There is a need to increase attention to this vulnerable group of women who are living in dysfunctional and violent relationships. ${ }^{18}$ Millennium Development Goals (MDG)-3 addresses the promotion of gender equity and women empowerment, but continuous occurrence of violence toward women is not consistent with the commitment. Gender equity is recognized to be a key strategy toward achieving all the MDG goals as pointed out in the interim report. Development policies that fail to take gender inequality into account or that fails to enable women to the actors in those policies and actions will have limited effectiveness and serious costs to the societies. ${ }^{19}$ IPV adds substantially to healthcare costs both for direct services to treat the injuries and higher utilization of a wide range of healthcare services. Healthcare providers, particularly those who care for pregnant women, are in a unique position to identify these women and direct them and their families to the help they need to end the violence in their lives. ${ }^{20}$

Medical, health and surgical services for pregnant women should consider screening for IPV, and providers should be aware that IPV victims are at increased risk for adverse outcomes. Services should also develop links with the Battered Women's Movement; such programmes now exist in many countries. ${ }^{21}$ Very few women seek support from the health sector, and the health system is not proactive in identifying and supporting women at risk. A greater commitment to making the health system responsive to women in distress is essential and should be undertaken with the same level of commitment given to prevention programmes. $^{22}$

The high levels of domestic violence during pregnancy highlight the need to develop screening and intervention strategies at this time. Further, women should be screened not only for physical violence but also psychological violence given that psychological violence may result in distinct negative consequences. Educating and empowering women and upgrading their socioeconomic status may abate the incidence of IPV. There is a need of integrating services to such victims by a team of women help groups, psychiatrists, counsellors, police, legal aids, and medical social workers. The question which still remains unanswered after so much research done is whether there is any permanent effective social intervention to protect such affected women of reproductive age who must be given utmost attention during vulnerable periods of their life. Thus intervention trials or clinical trials which can give assuring psychosocial interventions in prevention of domestic violence should be promoted.

\section{REFERENCES}

1. Krug EG, Dahlberg LL, Mercy J, Zwi AB, Lozano R. World report on violence and Health. In: WHO, eds. WHO Report. Geneva: WHO; 2002: 1-331.

2. WHO. Violence and injury prevention: prevention of intimate partner and sexual violence (domestic violence), 2014. Available at: http://www.who.int/violence_injury_prevention/viol ence/sexual/en/.

3. World Health Organization. Violence against women: definition and scope of the problem, 2014. Available at: http://www.who.int/gender/violence/v4.pdf. Accessed 21 April 2014.

4. WHO. Intimate partner violence during Pregnancy, 2011. Available at: www.who.int/reproductivehealth. WHO_RHR_11.35_eng.pdf

5. Mahapatro M, Gupta RN, Gupta V, Kundu AS. Domestic violence during pregnancy in India. J Interpers Violence. 2011;26(15):2973-90. 
6. Indian Institute of Population Sciences. National family health survey report 3, 2014. Available at: http://www.hetv.org/india/nfhs/nfhs3/NFHS-3Domestic-Violence.pdf. Accessed 5 April 2014.

7. Cha S, Masho SW. Intimate partner violence and utilization of prenatal care in the United States. J Interpers Violence. 2014;29(5):911-27.

8. Jasinski JL. Pregnancy and domestic violence: a review of the literature. Trauma Violence Abuse. 2004;5(1):47-64.

9. Devries KM, Kishor S, Johnson H, Stockl H, Bacchus LJ, Garcia-Moreno C, et al. Intimate partner violence during pregnancy: analysis of prevalence data from 19 countries. Reprod Health Matters. 2010;18:158-70.

10. Kimuna SR, Djamba YK, Ciciurkaite G, Cherukuri $S$. Domestic violence in India: insights from the 2005-2006 national family health survey. J Interpers Violence. 2013;28:773-807.

11. James L, Brody D, Hamilton Z. Risk factors for domestic violence during pregnancy: a metaanalytic review. Violence Vict. 2013;28(3):359-80.

12. Sabarwal S, McCormick MC, Subramanian SV, Silverman JG. Son preference and intimate partner violence victimization in India: examining the role of actual and desired family composition. Biosoc Sci. 2012;44(1):43-56.

13. Chambliss LR. Intimate partner violence and its implication for pregnancy. Clin Obstet Gynecol. 2008;51(2):385-97.

14. WHO. Executive summary: global and regional estimates of violence against women: Prevalence and health effects of intimate partner violence and non-partner sexual violence, 2014. Available at: http://www.apps.who.int/iris/ bitstream/10665/85241/1/WHO_RHR_HRP_13.06_ eng.pdf?ua=1. Accessed 1 April 2014.

15. Mahenge B, Likindikoki S, Stöckl H, Mbwambo J. Intimate partner violence during pregnancy and associated mental health symptoms among pregnant women in Tanzania: a cross-sectional study. BJOG. 2013;120(8):940-6.

16. Raj A, Sabarwal S, Decker MR, Nair S, Jethva M, Krishnan $\mathrm{S}$, et al. Abuse from in-laws during pregnancy and post-partum: qualitative and quantitative findings from low-income mothers of infants in Mumbai, India. Matern Child Health J. 2011;15(6):700-12.

17. Sarkar NN. The impact of intimate partner violence on women's reproductive health and pregnancy outcome. J Obstet Gynecol. 2008;28(3):266-71.

18. Finnbogadóttir H, Dykes AK, Wann-Hansson C. Prevalence of domestic violence during pregnancy and related risk factors: a cross-sectional study in southern Sweden. BMC Women's Health. 2014;14:63.

19. WHO. addressing violence against women and achieving millennium development goals. Geneva: WHO; 2005.2 Available at: http://www.who.int/gender/documents/violence/ who_fch_gwh_05_1/en/. Accessed 11 March 2014.

20. Chambliss LR. Intimate partner violence and its implication for pregnancy. Clin Obstet Gynecol. 2008;51(2):385-97.

21. Hassan M, Kashanian M, Hassan M, Roohi M, Yousefi H. Maternal outcomes of intimate partner violence during pregnancy study in Iran. Public Health. 2014;128(5):410-5.

22. Jejeebhoy SJ, Santhya KG, Acharya R. Violence against women in South Asia: the need for the active engagement of the health sector. Glob Public Health. 2014;9(6):678-90.

DOI: 10.5455/2394-6040.ijcmph20141101

Cite this article as: Shidhaye PR, Giri PA. Domestic violence during pregnancy: a neglected and unseen public health problem. Int J Community Med Public Health 2014;1:1-3. 